\title{
1 Bistable host-pathogen interaction explains varied infection outcomes
}

\author{
2 Guozhi $\mathrm{Yu}^{1,2} *$, Yingying $\mathrm{Hu}^{1}$, Shizhong $\mathrm{Wang}^{1}$, Xingfa $\mathrm{Han}^{1}$, Xiaggang $\mathrm{Du}^{1}$, Huailiang $\mathrm{Xu}^{1}$, Xianyin Zeng ${ }^{1}$, \\ 3 Ulrich Steiner ${ }^{3}$ Jens Rolff ${ }^{2}$ \\ $4{ }^{1}$ College of Life Science, Sichuan Agricultural University, Xinkang Road 46, 625014 Ya'an, China \\ $5{ }^{2}$ Evolutionary Biology, Institut für Biologie, Freie Universität Berlin, Königin-Luise Strasse 1-3, 14195 Berlin, \\ 6 Germany \\ $7{ }^{3}$ Evolutionary Demography, Institut für Biologie, Freie Universität Berlin, Königin-Luise Strasse 1-3, 14195 Berlin, \\ 8 Germany
}

ABSTRACT: Death or survival are the two outcomes of an infection. The development of an infection depends on multiple interplaying factors, including the temporal dynamic of host nutrition, immune response and pathogen proliferation, but how these factors collectively determine the outcome of an infection is less understood. To understand the underlying principle of infection, here, we took a systems approach by developing a simple mathematical model to understand multi-factored host-pathogen interaction. We find that nonlinear interactions feedback between host and pathogens resulting in two distinct trajectories of disease progression. We show that disease progression, measured by the pathogen load, responds in a bistable manner, by either proliferating or eventually being eliminated. We identified key processes accounting for bistability, including host's resource assimilation, immune response and intrinsic noise. In addition, resource availability, immunity, and pathogen load at the onset of infection are also critical in determining the bistability. We then highlight, by discussing in the light of previous theoretical and experimental work, how our framework provides testable theories for host-pathogen interaction 


\section{INTRODUCTION}

29 Infected hosts either die or survive. The progression of an infection and its symptoms depend on

30 various factors that have been qualitatively examined in numerous ecological immunology studies [1-5].

31 For example, manipulating nutrition and resource availability mediates host resistance and tolerance to

32 pathogen infection, and thereby determines the course of infection [3,6-8]. Hosts consuming protein-

33 rich diet resist bacterial infection more efficiently and survive better than hosts on a protein-deprived

34 diet $[9,10]$. The protein-rich diet enhances the production of immune effectors such as antibodies [11]

35 and antimicrobial peptides [5]. Carbohydrate-rich food by contrast can reduce the host's ability to

36 eradicate pathogens but may result in hosts harboring more pathogens before the onset of symptoms [5],

37 but see [13]. Experiments on diet-restriction, diet choice and metabolic shift during infection have also

38 highlighted the significant role of resource and nutrition in host immunity [6,14-17]. In addition, the

39 genetic background of both host and pathogen can affect the outcome of infections even within the

40 same or closely related species [18]. For instance, hosts with varied and diversified expression of

41 antimicrobial peptides differ in their ability in either resisting or tolerating pathogens [19-21].

43 To disentangle the contribution of multiple factors on the outcome of infection, a common approach is

44 to analyze experimental studies that apply a full-factorial design by general linear models. However,

45 such analyses have been criticized as they are limited to linear treatment-response hypotheses, single

46 time point sampling, and their difficulties in inferring causality [22-24]. Within-host pathogen

47 dynamics tend to be nonlinear, which means response variables do not proportionately change with

48 explanatory factors or time $[25,26]$. For example, the progression of malaria infections in mice revealed

49 damped oscillations of both pathogen load and blood immune cell count [27]. In other words, both the

50 pathogen population and host's health fluctuate during the course of an infection. Measuring multiple

51 response variables of the same host at different time points during infection clearly revealed such

52 temporal dynamics [34]. Another important form of non-linearity is bistability, for which the pathogen

53 load and host health are eventually attracted to two "steady states" corresponding to the death and

54 survival of the host, respectively [25]. Empirical data, combined with mathematical analyses, revealed

55 that the progression of infection and health dynamics in a number of hosts show this pattern [25,28-30].

56 However, in lab experiments, such within-host temporal dynamics can be masked in small animal

57 models that cannot be sampled more than once, for instance when sampling is destructive. Pooled

58 sampling, by sacrificing enough individuals at each time point, still revealed bistability in pathogen 
59 load in Drosophila melanogaster [31]. In experiments with a defined inoculum, pathogens firstly

60 propagate, then either reach the carrying capacity of the host, or decrease to very low level. This

61 divergence beginning at some time point can be shown with time series data [31].

63 Therefore, a theoretical and practical framework of host-pathogen interactions and feedbacks could

64 provide an understanding of the within-host infection dynamics $[28,32,33]$. By including the concept of

65 within-host resource competition in host-pathogens dynamics, researchers have built models that

66 capture the distribution of host resources in an infection [32,34]. Possible feedbacks between resource,

67 host immunity, and pathogens are likely to be the vital factors affecting the dynamics. To gain a

68 quantitative understanding of within-host dynamic of infection, we extend the within-host resource-

69 centric framework to host-pathogen interactions and their feedbacks. Our framework integrates the type

70 of infection, and the regulation of the pathogen load inside the host via host resources. Our model

71 recapitulates that host fitness is reduced when the pathogen load is high, i.e. causing sickness

72 behaviors or changing food consumption. The host immune system is activated by pathogen invasion,

73 and immediately targets and finally can eliminate the pathogens, mediated by metabolic adjustment.

74 Most importantly, the energetic and resource costs of the dynamics are balanced by the host's ingestion

75 and metabolism. Thus, we expect a tipping point in the dynamics that differentiates the sustainability

76 and collapse of the system, which also determines the survival or death of the host. In order to explain

77 the phenomenon, we build a simple mathematical model that involves three major components in

78 infection: resource assimilation of host, immune response of host and within-host dynamics of the

79 pathogen. We propose that a feedback loop among those three components governs the progression and

80 consequence of disease and infection and can yield a bistable outcome.

\section{MATERIAL AND METHODS}

\section{A model of resource flow within the host}

84 Here, we build a model based on the flow of within-host energetics/resources (thereafter resources) to 85 understand infection dynamics. This view is motivated by several recent empirical studies [6,35-37].

86 For the host to maintain its energy and resource balance during infection, we assume that host's

87 intrinsic resources are drained in three ways: basic metabolism, immune response, and pathogen 
88 replication. Upon infection, host switches metabolism to distribute the energy and resources to combat

89 pathogens [16] (Fig. 1).

91 In our model, hosts convert the ingested food, $C$, at an arbitrary rate, $\alpha$, into instantaneously usable 92 resources, $R$ (see also Table $\mathrm{S} 1$ for all parameter definitions). The assimilation rate under infection is 93 reduced by $\phi$, which represents the virulence of pathogens: host assimilation under infection is $94 \alpha(1-\phi)$. We include this term of host assimilation under infection by assuming that bacterial 95 endotoxins can block host metabolic functions, and hence host resource conversion and assimilation.

96 Host resources, $\mathrm{R}$, are used at rate $\delta_{R}$ for maintaining metabolism, and at rate $\lambda$ for immune defense.

97 The host immune defense includes the production of immune effectors $I$, such as antimicrobial peptides 98 and white blood cells, that use up resources. With the above assumptions, the rate of resource change 99 can be written as

$$
\frac{d R}{d t}=\alpha C(1-\phi)-\delta_{R} R-\lambda I R
$$

100 Once infected with pathogens, the host immune system responds to the infection by allocating 101 resources to produce immune effectors $I$. The absolute quantity of immune factors scales to the 102 pathogen density. We link the production rate of immune factors, $\beta$, to resource $R$ and pathogen load $P$, 103 by $\beta R P I$. At the same time, immune effectors are also removed by decay, for example they are 104 metabolized, with rate $\delta_{I}$. The rate of immune effector change is described as:

$$
\frac{d I}{d t}=\beta \lambda R P I-\delta_{I} I
$$

105 We first consider pathogen growth to be resource independent, but dependent on the carrying capacity 106 inside the host. A more comprehensive interaction between host and pathogen will be discussed later. 107 The rate of pathogen growth is described by the following relation,

$$
\frac{d P}{d t}=\gamma P\left(1-\frac{P}{\Omega}\right)-\delta_{P} I P
$$

108 where $\gamma$ is the arbitrary growth rate of pathogens, which is limited by the carrying capacity of the host $109 \Omega$ (if not by the availability of host resources). Pathogens are removed by the immune effectors with 110 rate $\delta_{P}$ and the natural death of pathogen can be neglected. 


\section{The types of feedback interactions between pathogen and host}

113 The assimilation and distribution of host resource are also constrained by the feedback of pathogens.

114 Different pathogens may consume host resource to different extend. Some pathogens consume 115 considerable amounts of host resources, such as parasitic wasps and bacteria in some insect hosts $116[15,17]$, or Plasmodium and gastrointestinal helminths in vertebrates [38]. Apart from eliciting immune 117 responses, the propagation of pathogen and/or pathogen-related toxins can undermine the resource in118 take or assimilation of the host, such as reducing foraging and slowing down metabolism, which 119 subsequently will result in host death. Here we focus on host exploitation by pathogens consuming host 120 resources or directly producing pathogenic factors to harm the host, we categorize the interactions 121 between host and pathogen into three types: a pathogen consumes host resources and disrupt the host's 122 metabolic functions (A), a pathogen only consumes host resources (B), and a pathogen disrupts the 123 host's metabolic functions without consuming many resources (C).

125 In type A interactions the pathogen consumes host resources at rate $\epsilon$. In addition, the pathogen disrupts 126 host metabolism by reducing the assimilation of resource $\mathrm{R}$, and the inhibition function $\phi$ is dependent 127 on the pathogens; $\phi=P /\left(P+\Theta_{P \rightarrow R}\right)$, where $P$ is pathogen load and $\Theta_{P \rightarrow R}$ is the half-saturation 128 threshold of the pathogen that impairs the flow of resources inside the host. Experiments show that the 129 immune response to pathogen infection dose does not increase proportionately with the pathogen load 130 [35]. We model the immune response with respect to pathogen load by $\beta P^{\kappa} /\left(P^{\kappa}+\Theta_{P \rightarrow I}^{\kappa}\right)$. $\kappa$ is a Hill 131 coefficient, and $\Theta_{P \rightarrow I}$ is the half saturation threshold of pathogen to elicit an immune response. Immune 132 effectors, such as antimicrobial peptides, kill pathogens in a nonlinear fashion [45]. The death rate of 133 pathogens has the form $\delta_{P} I^{\eta} /\left(\Theta_{I \rightarrow P}^{\eta}+I^{\eta}\right) . \eta$ is also a Hill coefficient, and $\Theta_{I \rightarrow P}$ is the half saturation 134 threshold of immune effectors to kill pathogens. Moreover, we assume that pathogen growth depends 135 on the availability of resources as pathogens consume considerable resources. Modifying equation 1, 136 equation 2 and equation 3 in the light of these assumptions, we obtain the full model of type A 137 interaction with following dynamics: 


$$
\begin{gathered}
\frac{d R}{d t}=\alpha C\left(1-\frac{P}{P+\Theta_{P \rightarrow R}}\right)-\delta_{R} R-\lambda I R-\epsilon P R, \\
\frac{d I}{d t}=\frac{\beta \lambda R I P^{\kappa}}{P^{\kappa}+\Theta_{P \rightarrow I}^{\kappa}}-\delta_{I} I, \\
\frac{d P}{d t}=\gamma \epsilon R P\left(1-\frac{P}{\Omega}\right)-\frac{\delta_{P} P I^{\eta}}{\Theta_{I \rightarrow P}^{\eta}+I^{\eta}} .
\end{gathered}
$$

\section{8}

139 In Type B interaction, the host resource intake, $C$, and assimilation rate, $\alpha$, are assumed independent of

140 pathogen load as the pathogen causes little or no harm to the host metabolic functions. Pathogens

141 consume resources from the host, and pathogen growth is thus resource dependent. Immune response

142 and pathogens elimination also follow a Hill Function. For those pathogens that fall into this category,

143 the host pathogen interaction can be captured by (also see Fig.1 and Fig. S3):

$$
\begin{gathered}
\frac{d R}{d t}=\alpha C-\delta_{R} R-\lambda I R-\epsilon P R, \\
\frac{d I}{d t}=\frac{\beta \lambda R I P^{\kappa}}{P^{\kappa}+\Theta_{P \rightarrow I}^{\kappa}}-\delta_{I} I, \\
\frac{d P}{d t}=\gamma \epsilon R P\left(1-\frac{P}{\Omega}\right)-\frac{\delta_{p} P I^{\eta}}{\Theta_{I \rightarrow P}^{\eta}+I^{\eta}} .
\end{gathered}
$$

\section{4}

145 In Type $\mathrm{C}$ interaction, the pathogen sabotages host metabolic functions, but consumes little resources

146 from the host. The growth of pathogen is therefore independent of host resources. With similar 147 assumptions as above regarding immune responses and pathogen elimination, we use the following 148 equations to capture the interaction:

$$
\begin{gathered}
\frac{d R}{d t}=\alpha C\left(1-\frac{P}{P+\Theta_{P \rightarrow R}}\right)-\delta_{R} R-\lambda I R, \\
\frac{d I}{d t}=\frac{\beta \lambda R I P^{\kappa}}{P^{\kappa}+\Theta_{P \rightarrow I}^{\kappa}}-\delta_{I} I, \\
\frac{d P}{d t}=\gamma P\left(1-\frac{P}{\Omega}\right)-\frac{\delta_{P} P I^{\eta}}{\Theta_{I \rightarrow P}^{\eta}+I^{\eta}} .
\end{gathered}
$$

150 Consequently, if the host rapidly eliminates the pathogen or keeps the pathogen under threshold level 151 and is symptom free, it will eventually survive, as long as basal metabolism does not exceed 
152

153

154

consumption and assimilation efficiency. Occasionally, the host could also maintain very high pathogen load while showing no or rather mild symptoms of infection which usually indicates high "tolerance" of the host. If pathogens are less resource costly, keeping large numbers of pathogens inside the body requires the host having an efficient turn-over of food into within host resources to clear toxic substance and repair host damage generated by pathogens. Thus, it is crucial for a host to balance the cost of maintaining high metabolic activity and reducing the damage of pathogen.

\section{Model analysis and simulation}

Using the models described above, we analyzed how the different parameter settings determine the final infection outcome within a host. We solve the equations numerically with sets of parameters and initial conditions (table S1). To examine the bistable infection outcomes of host individuals, we simulated dynamics of infection in individuals with four varied initial conditions $\left(\mathrm{R}=10^{\wedge} 0, \mathrm{I}=10^{\wedge} 0, \mathrm{P}\right.$ $=10^{\wedge} 4.99 ; \mathrm{R}=10^{\wedge} 0, \mathrm{~K}=10^{\wedge} 0, \mathrm{P}=10^{\wedge} 0 ; \mathrm{R}=10^{\wedge} 6, \mathrm{~K}=10^{\wedge} 6, \mathrm{P}=10^{\wedge} 4.99 ; \mathrm{R}=10^{\wedge} 6, \mathrm{~K}=10^{\wedge} 6, \mathrm{P}=$ $\left.10^{\wedge} 0\right)$.

To explore the criticality and sensitivity of the interaction, we numerically solved the system until the steady states are reached. The steady states are identified when the difference of solutions between two time points are less than $10^{\wedge}-5$. We then record the pathogen load at the end of each simulation and analyzed the bistability across simulations. To broadly explore how the initial settings of resource level, immunity and pathogen load affect the infection outcomes, we set an orthogonal combination of three initial conditions ranging from $10^{\wedge} 0$ to $10^{\wedge} 5$. We then identified two infection trajectories by monitoring the pathogen load. If the pathogen load reaches the host's carrying capacity, the trajectory is classed as "death", otherwise as "survival".

To investigate how intrinsic noise affect the dynamics of infection, we ran simulations by adding a noise term to each of the states in the deterministic model. For each simulation we drew one random number from a normal distribution with mean 0 and variance of $\sigma^{2}$. We ran 500 simulations for each noise level, and explored noise levels between values of $10^{\wedge}-5$ to $10^{\wedge}-2$. We repeated these sets of simulations for each of the three initial parameter settings, resource assimilation, immune response, and pathogen load.

In order to simulate the bimodal distribution of pathogen load in experiments, we ran simulations by drawing the parameter value of resource assimilation from a uniform distribution $\alpha \sim \mathrm{U}[1500,1700]$, 
182

183

184

185

186

187 Bistable infection outcomes

188 We modeled the in-host infection dynamic of simple interactions among three components: the flow of 189

and the parameter value of immune response from a logarithmic uniform distribution $\lambda \sim 10^{\wedge} \mathrm{U}[2,5]$. Such draws were conducted for 5000 samples. We then recorded the pathogen load at different time points in each replicate. All the calculations and simulations are implemented in R 3.6.0. within-host resources, immune response, and pathogen load (Fig. 1a). Our analysis showed that the interactions of these three components collectively determines the outcome of the infection. In particular, disease progression falls into two different trajectories: (a) pathogen load increases to the maximum and (b) a decline of pathogen load to some controlled level that resembles a chronic infection (Fig. 1b, Fig. 1c). This pattern reveals a typical pattern of bistability. Resource supply, immune activation, and pathogen load, follow two distinct trajectories which determine death or survival of the host (Fig. S1, Fig. S2).

Our analysis also showed that host resource assimilation and the strength of the immune response are two important contributors for the bistable pattern of an infection (Fig. 1d, Fig. 1e). If the rate of resource assimilation and immune response is lower than the threshold level, the pathogen population will grow to high titres that can lead to the death of the host. If the rate of resource assimilation and immune response is at intermediate levels, the pathogen either propagates or is controlled. If the rate of resource assimilation and immune response is above threshold levels, the pathogen will always be controlled (Fig.1d, Fig. 1e).

Different pathogens manipulate hosts in different ways by controlling the regulatory relations among host resource assimilation, host immune response, and pathogen virulence. Our analysis further revealed that the ways how different pathogens manipulate hosts does not qualitatively change the bistable outcome of the host pathogen interaction (Fig. S3). 
210 Initial levels of resource, immunity and pathogen load before infection determine the infection 211 trajectory

212 Immune challenge and environmental stress can alter reservoirs of host resources and levels of host 213 immunity prior to infection. One would also expect that immune challenged hosts having a higher level 214 of basic immunity are likely to survive another infection. We investigated whether changes or 215 variations in initial host immunity and resource reservoir conditions together with pathogen load would 216 impact the outcome of infection. By fixing the rates of resource assimilation and immune reaction, we 217 find that the dynamics of infection are sensitive to the initial conditions of level of immunity, the 218 availability of resources, and pathogen load before infection (Fig. 2a, Fig 2b). Sampling across a wide 219 range of the three initial parameters — immune response, pathogen load and host resources —in our 220 model, we found that increased initial immunity increased host survival, higher initial pathogen load 221 increased host mortality, however, the initial resource reservoir did not affect survival probabilities(Fig 222 2c). We assessed combined effects of initial parameter settings and thereby revealed that small 223 differences in quantity of the combinations can result in distinct infection trajectories (Fig. S4) in 224 certain ranges.

\section{Intrinsic noise fosters bistability}

227 We next examined whether intrinsic noise leads to bistable infection outcomes. First, we fixed the deterministic system at a state that pathogen will not be cleared. Then, we introduced a noise term either into resource assimilation, immune reaction, or pathogen growth. We found that when the noise level is low, the system will maintain the previously set state, in which the infection is acute and the pathogen will not be cleared. As the noise level increase, the system either falls into the controlled state, in which pathogen will be kept at low abundance and the host suffers chronic infection, or into the uncontrolled state, in which the pathogen will grow and the host suffers acute infection. In addition, our results show that noise in resource assimilation, immune response, and pathogen growth all contribute to bistability in the infection outcomes at the critical level (Fig. 3).

\section{Bistability leads to variations in pooled time-series data}

238 In Fig. 4 we simulated the progression of infection and in-silico sampled the bacterial load at different 239 time points in host individuals. In the pooled data, bacterial load diversified after initial infection, 
240 reached considerably variable bacteria load at some intermediate time points during progression, before

241 finally converging to a bimodal distribution. Variations in bacterial load create differences with several

242 orders of magnitude. We then explored two different parameters settings: a) fixed initial conditions

243 with varied rates of resource assimilation and immune response, and b) varied initial condition with

244 fixed rates of resource assimilation and immune response. In both cases, the pathogen load in hosts

245 sampled at different time points first followed the same pattern, a unimodal distribution, followed by a

246 bifurcation, i.e. splitting into a bimodal distribution (Fig 4).

\section{DISCUSSION}

249 In this study, we modeled a feedback in host resource assimilation, host immune response and pathogen 250 performance. These parameters interacted and generated bistable infections that lead to either survival 251 or death of the host. In particular, the bistability of our model depends on the rates of immune response 252 and metabolism as it is highly sensitive to the rate parameters, $\alpha$ and $\beta$. This may be the result of 253 collective effects of the underlying molecular mechanisms, for example, spontaneous gene up254 regulation during infection could shift hosts to the survival trajectory [16]. In addition, immune 255 responses, such as the expression of antimicrobial peptides, tend to show correlated spatial and 256 temporal patterns during infection [16]. Moreover, a recent study investigating a densely sampled time257 series of whole genome transcriptomics in Drosophila found that genes in the same "functional 258 clusters" displayed correlated expression patterns during the course of infection [40]. Also, pathogens 259 can manipulate the host response by reducing the resource assimilation of the host, a reduction in food 260 intake and compromised metabolism [17,35,41]. Reduced resource assimilation subsequently lowers 261 host condition and decreases the ability to maintain homeostasis and to clear infections. This is partially 262 due to toxic factors released by pathogens. Pathogens producing no toxic factors, but directly 263 competing for resources with the host, may also compromise host condition and can result in the same 264 bistable outcome (Fig S3). In line with previous theoretical studies that highlight resource availability 265 for fighting and tolerating pathogens [17,35,41], our simple model captures the feedbacks among 266 immunity, pathogens, and host resources and explains the survival and death of host in an infection. We 267 highlight that the feedbacks among host resource, pathogen load, and the ability to maintain immunity 268 are potentially key mechanisms to determine the infection outcome. 
270 Our model found that bistability of host-pathogen interactions is very sensitive to initial conditions. For

271 example the baseline of immunity and resources, are critical for determining the bistable infection

272 outcome. Variations of baseline immunity, resource, and pathogen load can be the result of differential

273 food supply or prior pathogen exposure. Changes in baseline immunity are commonly observed in

274 studies on "memory effects" of invertebrate immune systems [42,43]. Although our model, together

275 with published experimental work, finds that higher levels of baseline immunity lead to better infection

276 outcomes, there is still large uncertainty and variation at the individual level. Slight differences in the

277 combination of initial conditions (immunity, resource, and pathogen load) will lead to distinct

278 trajectories of life and death (Fig. 2 A, 2B). It is known that most immune challenges up-regulate

279 cellular and humoral immunity, but it probably changes levels of other physiological aspects such as

280 carbohydrate and amino acids resources, before the whole system reverts to homeostasis [44]. To

281 observe the divergent infection outcomes, we propose that future experiments could be designed to

282 monitor a variety of related physiological states with reasonable time-resolution, which would also

283 require large sample sizes [31,40,44].

285 Our model also finds that pathogen load sampled from different host individuals at different time points

286 varies substantially, a finding commonly observed in experiments [15,27,31,35,45-49]. We reason that

287 this variation could result from the bistable characteristics. In large animal models, for example

288 following Plasmodium infection in individual mice revealed distinct damped oscillating pattern of

289 pathogen load within the host [27,50]. However, for smaller model hosts such as Drosophila,

290 continuously monitoring pathogens dynamics in the same individuals is largely constrained. To

291 circumvent these constraints, researchers sampled pooled times series data from different individuals at

292 the same time point $[31,45]$. This causes large variations in pathogen distribution even in precisely

293 controlled experimental conditions. Sampling pathogen loads with finer time-resolution revealed

294 bifurcating pathogen loads and their consequence of bistable outcome. Our model seeks to explain this

295 phenomenon. We suggest that the nonlinear characteristics of the host-pathogens interaction might be

296 sufficient to generate these bistable outcomes. Individual hosts could progress along different infection

297 trajectories, for which pathogen load varies at single time points. We further examined the stochastic

298 nature within the host and found that small internal perturbations of immune responses and resource

299 metabolism could drive the infection from the one steady state to another. 
301 We also investigated how different type of pathogens influence the patterns of infection. Pathogens, 302 such as viruses, may cause severe harm to hosts, but consume little resources of hosts [51];

303 alternatively, they may cause little direct harm to the host, but consume large amount of resources of 304 hosts, for example in the case of helminth [52]. We separately implemented these distinct pathogens in 305 our model. Our results showed that the bistable nature of the infection dynamics does not qualitatively 306 change for different pathogens in our models.

308 In our model, solutions of states co-determined the trajectories of infection outcomes and recovered the 309 diagram of disease trajectories. Relating the change of pathogen load to the host's health is crucial to 310 understand the disease progression and provides insight into understanding concepts such as tolerance 311 vs. resistance. Researchers have shown a correlation between host health and pathogen load in time312 series data $[25,30]$. These correlations shape different trajectories on the "phase plane" that differentiate 313 survival and death of hosts. This is consistent with the idea that infection outcomes in various 314 circumstance are bistable. Moreover, correlating pathogen load with many other physiological and 315 immunological states essentially generate similar patterns. In short, many infection-related 316 physiological states together shape the nonlinearity of the in-host infection dynamics. Our model can 317 provide a mechanistic explanation for the distinct infection trajectories of the death-survival diagram $318[25,30]($ see also Fig S4).

320 We revealed the nonlinear interaction between host and pathogen, in which disease progression 321 followed two distinct trajectories which lead to death and survival of hosts. The catastrophic shift in 322 some critical parameters determines the death and survival of the host. Thus, it is crucial to identify 323 these critical conditions in which a catastrophic shift will happen. This includes tracking pathogen load, 324 host immunity, and nutrition level in real time. Treating infectious disease is to probe the non-linearly 325 dynamical system, and trying to delay the catastrophic shift by manipulating particular parameters. 326 Besides directly killing pathogens, these strategies also include using drugs to neutralize the toxic 327 substance secreted by the pathogens, which could substantially reduce the damage to the host and 328 increase host tolerance. Moreover, metabolic dysfunction, caused by infection, will drastically reduce 329 the host's ability to maintain homeostasis during infection. Extra supplement of energy may eventually 330 help overcoming the infection. These properties that emerge from a non-linear system should be taken 331 into consideration when developing a more comprehensive approach to treat infections. 
332 Note. At the final stage of writing this manuscript, a related work was brought to our attention: Stephen

333 P. Ellner, Nicolas Buchon, Tobias Dörr, Brian P. Lazzaro. Host-pathogen Immune Feedbacks Can

334 Explain Widely Divergent Outcomes from Similar Infections. bioRxiv. doi:

335 https://doi.org/10.1101/2021.01.08.425954

337 Disclosure of conflicts of interest: No potential conflicts of interest were disclosed.

339 Acknowledgments: We thank Dr. Alexandro Rodríguez-Rojas, Dr. Sophie Armitage and Dr. Désirée

340 Bäder for inspiring discussion at the early stage of this work.

342 Funding: This work was partially funded by grants from National Natural Science Foundation of 343 China with No. 32001242. 


\section{References:}

348 1. Haine, E. R., Moret, Y., Siva-Jothy, M. T.,Rolff, J. 2008 Antimicrobial defense and persistent infection in insects. Science 322, 1257-1259. (10.1126/science.1165265)

2. Jackson, J. A., Hall, A. J., Friberg, I. M., Ralli, C., Lowe, A., Zawadzka, M., Turner, A. K., Stewart, A., Birtles, R. J.,

Paterson, S., Bradley, J. E.,Begon, M. 2014 An immunological marker of tolerance to infection in wild rodents. Plos Biol.

3. Lynn, B. M. I., Scheuerlein, A.,Wikelski, M. 2003 Immune activity elevates energy expenditure of house sparrows: A link between direct and indirect costs? Proc. Roy. Soc. B. 270, 153-158. (10.1098/rspb.2002.2185)

4. Rolff, J.,Schmid-Hempel, P. 2016 Perspectives on the evolutionary ecology of arthropod antimicrobial peptides. Phil.

Trans. Roy. Soc. B 371, 20150297. (10.1098/rstb.2015.0297)

5. Kutzer, M. A. M.,Armitage, S. A. O. 2016 The effect of diet and time after bacterial infection on fecundity, resistance, and tolerance inDrosophila melanogaster. Ecol. Evol. 6, 4229-4242. (10.1002/ece3.2185)

6. Cumnock, K., Gupta, A. S., Lissner, M., Chevee, V., Davis, N. M.,Schneider, D. S. 2018 Host energy source is important for disease tolerance to malaria. Curr. Biol. 28, 1635-1642. (10.1016/j.cub.2018.04.009)

7. Galenza, A., Hutchinson, J., Campbell, S. D., Hazes, B.,Foley, E. 2016 Glucose modulates Drosophila longevity and immunity independent of the microbiota. Biol. Open 5, 165-173. (10.1242/bio.015016)

8. Becker, D. J., Streicker, D. G.,Altizer, S. 2015 Linking anthropogenic resources to wildlife-pathogen dynamics: A review and meta $\square$ analysis. Ecol. Lett. 18, 483-495. (10.1111/ele.12428)

9. Ponton, F., Wilson, K., Holmes, A. J., Cotter, S. C., Raubenheimer, D.,Simpson, S. J. 2013 Integrating nutrition and immunology: A new frontier. J. Insect Phys. 59, 130-137. (10.1016/j.jinsphys.2012.10.011)

10. Cotter, S. C., Littlefair, J. E., Grantham, P. J.,Kilner, R. M. 2013 A direct physiological trade-off between personal and social immunity. J. Anim. Ecol. 82, 846-853. (10.1111/1365-2656.12047)

11. Budischak, S. A., Hansen, C. B., Caudron, Q., Garnier, R., Kartzinel, T. R., Pelczer, I., Cressler, C. E., van Leeuwen, A.,Graham, A. L. 2017 Feeding immunity: Physiological and behavioral responses to infection and resource limitation. Front. Immunol. 8, 1914. (10.3389/fimmu.2017.01914)

12. Unckless, R. L., Rottschaefer, S. M.,Lazzaro, B. P. 2015 The complex contributions of genetics and nutrition to immunity in drosophila melanogaster. Plos Genet. 11, e1005030. (10.1371/journal.pgen.1005030) 
14. Povey, S., Cotter, S. C., Simpson, S. J.,Wilson, K. 2014 Dynamics of macronutrient self $\square$ medication and illness $\square$ induced anorexia in virally infected insects. J. Anim. Ecol. 83, 245-255. (10.1111/1365-2656.12127)

15. Ayres, J. S.,Schneider, D. S. 2009 The role of anorexia in resistance and tolerance to infections in drosophila. Plos Biol.

7, e1000150. (10.1371/journal.pbio.1000150)

16. Sanchez, K. K., Chen, G. Y., Schieber, A. M. P., Redford, S. E., Shokhirev, M. N., Leblanc, M., Lee, Y. M.,Ayres, J. S. 2018 Cooperative metabolic adaptations in the host can favor asymptomatic infection and select for attenuated virulence in an enteric pathogen. Cell 175, 146-158. (10.1016/j.cell.2018.07.016)

17. Bajgar, A., Kucerova, K., Jonatova, L., Tomcala, A., Schneedorferova, I., Okrouhlik, J.,Dolezal, T. 2015 Extracellular Adenosine Mediates a Systemic Metabolic Switch during Immune Response. Plos Biol. 13, e1002135. (10.1371/journal.pbio.1002135)

18. Lazzaro, B. P., Sackton, T. B.,Clark, A. G. 2006 Genetic variation in drosophila melanogaster resistance to infection: A comparison across bacteria. Genetics 174, 1539-1554. (10.1534/genetics.105.054593)

19. Unckless, R. L.,Lazzaro, B. P. 2016 The potential for adaptive maintenance of diversity in insect antimicrobial peptides.

Phil. Trans. Roy. Soc B 371, 20150291. (10.1098/rstb.2015.0291)

20. Hotson, A. G.,Schneider, D. S. 2015 Drosophila melanogaster Natural Variation Affects Growth Dynamics of InfectingListeria monocytogenes. G3 Genes|Genomes|Genetics 5, 2593-2600. (10.1534/g3.115.022558)

21. Vogel, H., Müller, A., Heckel, D. G., Gutzeit, H.,Vilcinskas, A. 2018 Nutritional immunology: Diversification and dietdependent expression of antimicrobial peptides in the black soldier fly Hermetia illucens. Dev. Comp. Immunol. 78, 141148. (10.1016/j.dci.2017.09.008)

22. Little, T. J., Shuker, D. M., Colegrave, N., Day, T.,Graham, A. L. 2010 The coevolution of virulence: Tolerance in perspective. Plos Pathog 6, e1001006. (10.1371/journal.ppat.1001006)

23. Ayres, J. S.,Schneider, D. S. 2012 Tolerance of infections. Annu. Rev. Immunol. 30, 271-294. (10.1146/annurevimmunol-020711-075030)

24. Råberg, L. 2014 How to live with the enemy: Understanding tolerance to parasites. Plos Biol. 12, e1001989. (10.1371/journal.pbio.1001989)

25. Torres, B. Y., Oliveira, J. H. M., Thomas Tate, A., Rath, P., Cumnock, K.,Schneider, D. S. 2016 Tracking resilience to

404 26. Graham, A. L.,Tate, A. T. 2017 Are we immune by chance? Elife 6. (10.7554/eLife.32783)

405 27. Mideo, N., Savill, N. J., Chadwick, W., Schneider, P., Read, A. F., Day, T.,Reece, S. E. 2011 Causes of variation in 406 malaria infection dynamics: Insights from theory and data. Am. Nat. 178, E174-E188. (10.1086/662670)

407 28. Louie, A., Song, K. H., Hotson, A., Thomas Tate, A.,Schneider, D. S. 2016 How many parameters does it take to 408 describe disease tolerance? Plos Biol. 14, e1002435. (10.1371/journal.pbio.1002435) 
409

29. Wale, N., Sim, D. G., Jones, M. J., Salathe, R., Day, T.,Read, A. F. 2017 Resource limitation prevents the emergence of drug resistance by intensifying within-host competition. Proc. Natl. Acad. Sci. U.S.A.. 114, 13774-13779. (10.1073/pnas.1715874115)

30. Lough, G., Kyriazakis, I., Bergmann, S., Lengeling, A.,Doeschl-Wilson, A. B. 2015 Health trajectories reveal the dynamic contributions of host genetic resistance and tolerance to infection outcome. Proc. Roy. Soc. B. 282, 20152151. $(10.1098 / \mathrm{rspb} .2015 .2151)$

31. Duneau, D., Ferdy, J., Revah, J., Kondolf, H., Ortiz, G. A., Lazzaro, B. P.,Buchon, N. 2017 Stochastic variation in the initial phase of bacterial infection predicts the probability of survival in D. Melanogaster. Elife 6. (10.7554/eLife.28298)

32. Cressler, C. E., Graham, A. L.,Day, T. 2015 Evolution of hosts paying manifold costs of defence. Proc. Roy. Soc. B. 282, 20150065. (10.1098/rspb.2015.0065)

33. FRANK, S. A. 2002 Immune response to parasitic attack: Evolution of a pulsed character. J. Theor. Biol. 219, 281-290. (10.1006/jtbi.2002.3122)

34. Tate, A. T.,Graham, A. L. 2015 Dynamic patterns of parasitism and immunity across host development influence optimal strategies of resource allocation. Am. Nat. 186, 495-512. (10.1086/682705)

35. van Leeuwen, A., Budischak, S. A., Graham, A. L.,Cressler, C. E. 2019 Parasite resource manipulation drives bimodal variation in infection duration. Proc. Roy. Soc. B. 286, 20190456. (10.1098/rspb.2019.0456)

36. Cressler, C. E., Nelson, W. A., Day, T.,McCauley, E. 2014 Disentangling the interaction among host resources, the immune system and pathogens. Ecol. Lett. 17, 284-293. (10.1111/ele.12229)

37. Canale, C. I.,Henry, P. 2011 Energetic costs of the immune response and torpor use in a primate. Funct. Ecol. 25, 557565. (10.1111/j.1365-2435.2010.01815.x)

38. Budischak, S. A., Wiria, A. E., Hamid, F., Wammes, L. J., Kaisar, M. M. M., van Lieshout, L., Sartono, E., Supali, T., Yazdanbakhsh, M.,Graham, A. L. 2018 Competing for blood: The ecology of parasite resource competition in human malaria-helminth co-infections. Ecol. Lett. 21, 536-545. (10.1111/ele.12919)

39. Johnston, P. R., Makarova, O.,Rolff, J. 2014 Inducible defenses stay up late: Temporal patterns of immune gene expression inTenebrio molitor. G3 Genes|Genomes|Genetics 4, 947-955. (10.1534/g3.113.008516)

40. Schlamp, F., Delbare, S. Y. N., Early, A. M., Wells, M. T., Basu, S.,Clark, A. G. 2020 Dense time-course gene expression profiling of the Drosophila melanogaster innate immune response. bioRxiv, 2020-2026. (10.1101/2020.06.25.172452)

41. Povey, S., Cotter, S. C., Simpson, S. J.,Wilson, K. 2014 Dynamics of macronutrient self-medication and illness-induced anorexia in virally infected insects. J. Anim. Ecol. 83, 245-255. (10.1111/1365-2656.12127)

42. Pham, L. N., Dionne, M. S., Shirasu-Hiza, M.,Schneider, D. S. 2007 A specific primed immune response in drosophila is dependent on phagocytes. Plos Pathog 3, e26. (10.1371/journal.ppat.0030026)

43. Hilker, M., Schwachtje, J., Baier, M., Balazadeh, S., Bäurle, I., Geiselhardt, S., Hincha, D. K., Kunze, R., MuellerRoeber, B., Rillig, M. C., Rolff, J., Romeis, T., Schmülling, T., Steppuhn, A., van Dongen, J., Whitcomb, S. J., Wurst, S., 

1118-1133. (10.1111/brv.12215)

444 44. Tate, A. T., Andolfatto, P., Demuth, J. P.,Graham, A. L. 2017 The within-host dynamics of infection in trans445 generationally primed flour beetles. Mol. Ecol. 26, 3794-3807. (10.1111/mec.14088)

446 45. Miller, C. V. L.,Cotter, S. C. 2018 Resistance and tolerance: The role of nutrients on pathogen dynamics and infection outcomes in an insect host. J. Anim. Ecol. 87, 500-510. (10.1111/1365-2656.12763)

46. Chambers, M. C., Lightfield, K. L., Schneider, D. S.,Vernick, K. D. 2012 How the fly balances its ability to combat different pathogens. Plos Pathog 8, e1002970. (10.1371/journal.ppat.1002970)

48. Chambers, M. C., Jacobson, E., Khalil, S.,Lazzaro, B. P. 2014 Thorax Injury Lowers Resistance to Infection in

49. Hanson, M. A., Dostálová, A., Ceroni, C., Poidevin, M., Kondo, S.,Lemaitre, B. 2019 Synergy and remarkable caused by induced changes in innate immune clearance of merozoites. Plos Comput. Biol. 10, e1003416. 
A

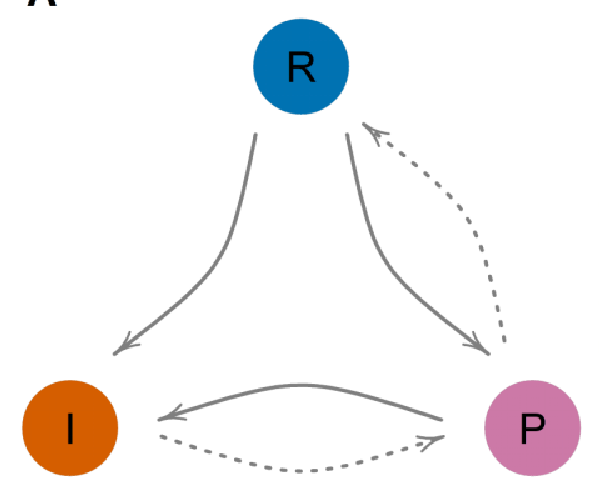

B

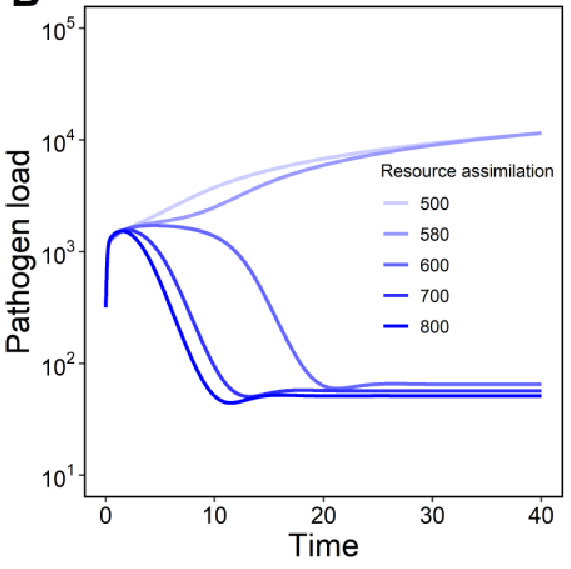

$E$
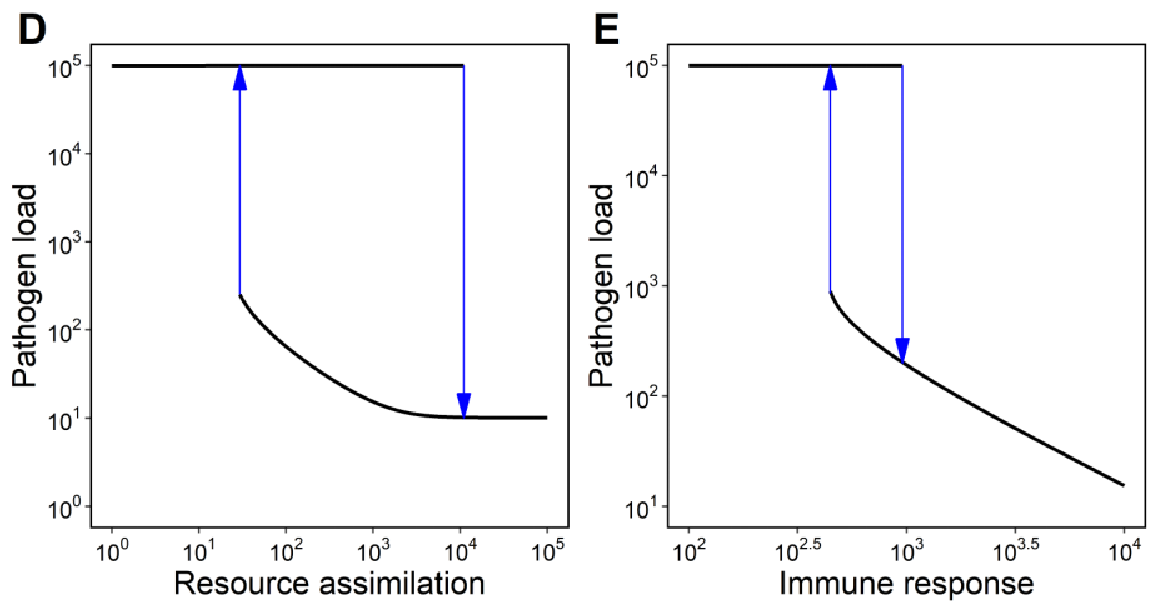

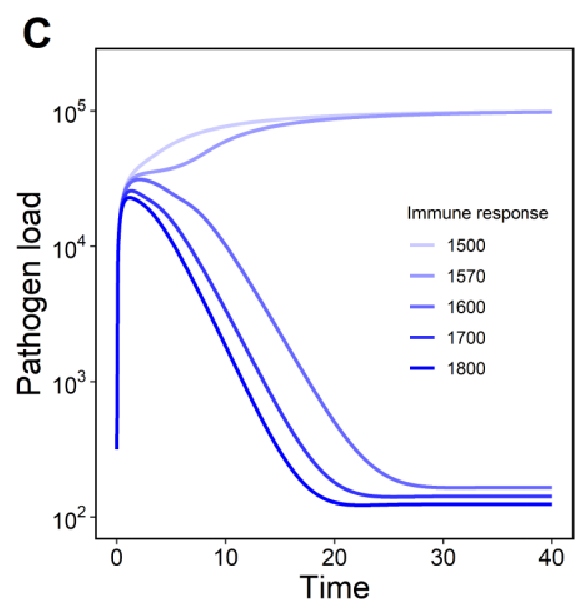

468

469 Fig. 1 The bistability or hysteresis of host-pathogen interaction. (A) A schematic illustration of a minimal model which encapsulates within-host interactions of resources, immunity, and pathogens 471 during the course of an infection. Solid arrows indicate positive interactions, while dashed arrows represent negative interactions. In such interaction with feedback loops, the pathogen population either propagates to the maximal carrying capacity of the host, or is reduced to a persistent low level dependent on resource assimilation, $\alpha$ (B), and immune response, $\beta(\mathrm{C})$. Numerical simulations with varied initial values of $\mathrm{P}, \mathrm{R}$ and I, show two distinct equilibria in terms of pathogen load across wide range of rate of resource assimilation (D) and Immune response (E). The four initial conditions are $\mathrm{R}=$ 478 $10^{\wedge} 0, \mathrm{I}=10^{\wedge} 0, \mathrm{P}=10^{\wedge} 4.99 ; \mathrm{R}=10^{\wedge} 0, \mathrm{~K}=10^{\wedge} 0, \mathrm{P}=10^{\wedge} 0 ; \mathrm{R}=10^{\wedge} 6, \mathrm{~K}=10^{\wedge} 6, \mathrm{P}=10^{\wedge} 4.99 ; \mathrm{R}=$ 
A

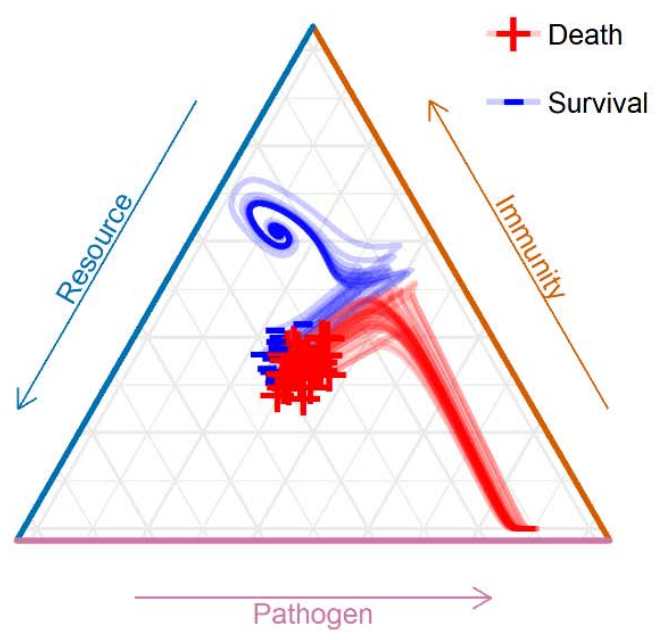

B

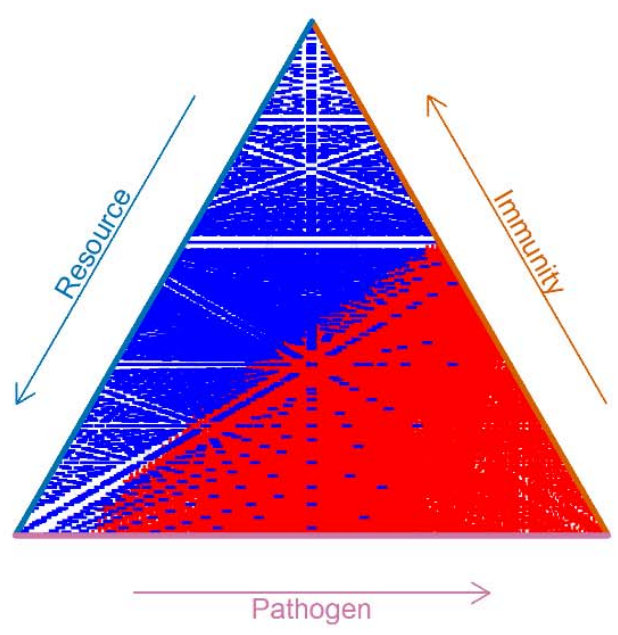

C

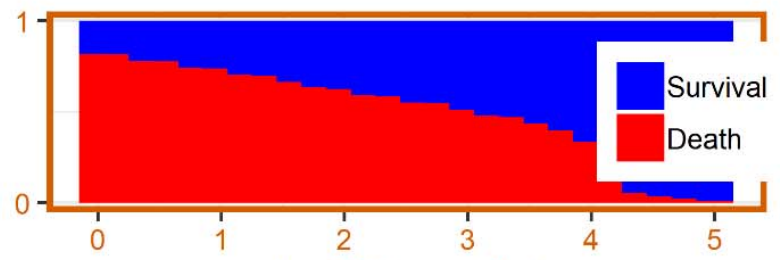

$\log 10($ Immunity)
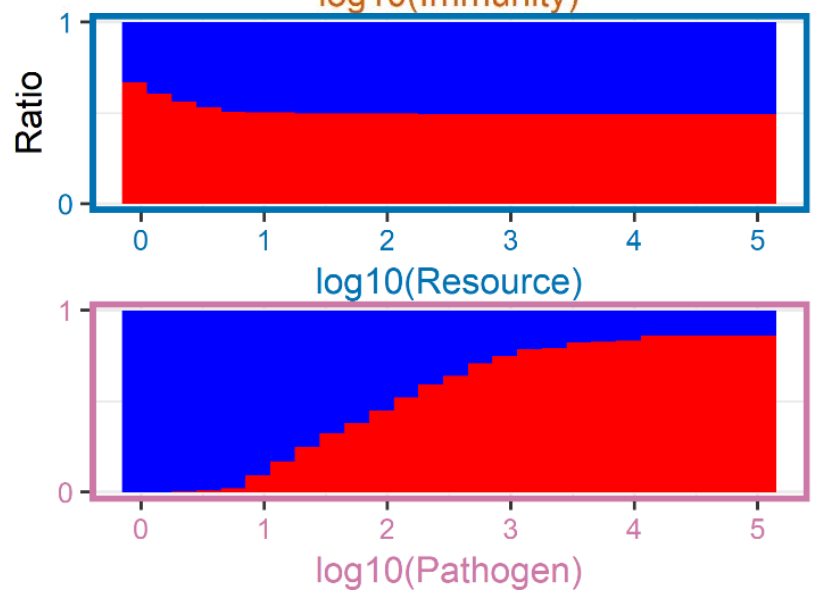

481 Fig. 2 Small variations in initial conditions determine distinct infection outcomes. (A, B) With identical 482 rate parameters, small differences in initial quantity of resource, immunity, and pathogen load will lead 483 to different disease trajectories during infection. (C) The pooled distribution of trajectories of death and 484 survival against initial parameter settings of immunity, resource, and pathogen. This suggests that a 485 wide range of initial level of these "state" will cause bimodal distribution of death and survival as the 486 consequence of an infection. The range of initial conditions for resource, immunity and pathogen are 487 all from $10^{\wedge} 0$ to $10^{\wedge} 5$. 
$\mathbf{A}_{10^{5}-}$

Resource assimilation

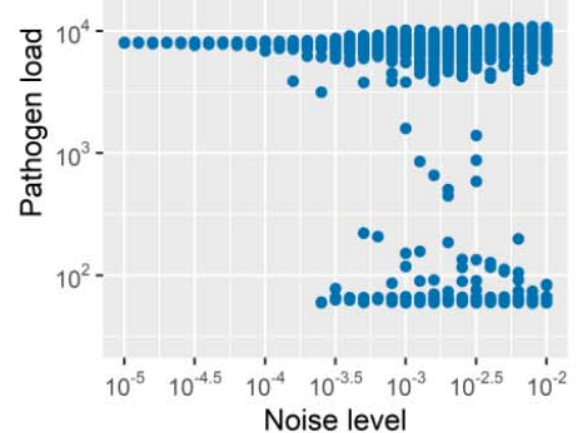

Noise level
B $_{10^{5}-}$

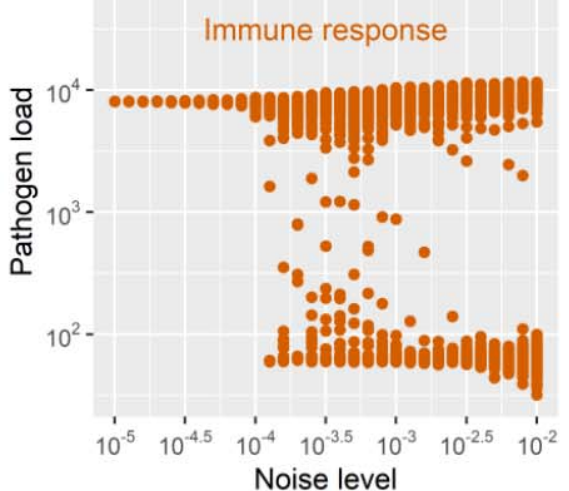

$\mathbf{C}_{10^{5}-}$

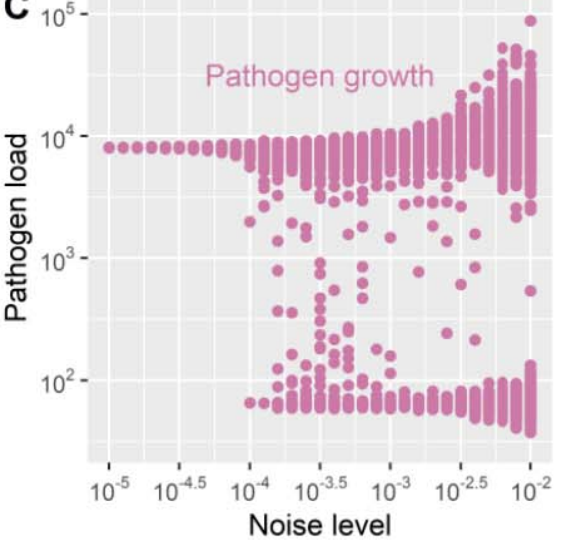

489 Fig.3 Intrinsic stochasticity or noise results in bistable infection outcomes. Perturbation of the 490 dynamics of infections changes the disease trajectories which resulted in bimodal distributions of 491 pathogens. When the noise level is low, all cases of infection have only one equilibrium in which 492 infection is acute and the pathogen load is high. As the noise increase, infection in some cases will be 493 controlled, in which the pathogen load is maintained lowly. Moreover, intrinsic noise in resource (A), 494 immunity (B) and pathogen growth (C) will all cause the same patterns of bimodal distribution. 

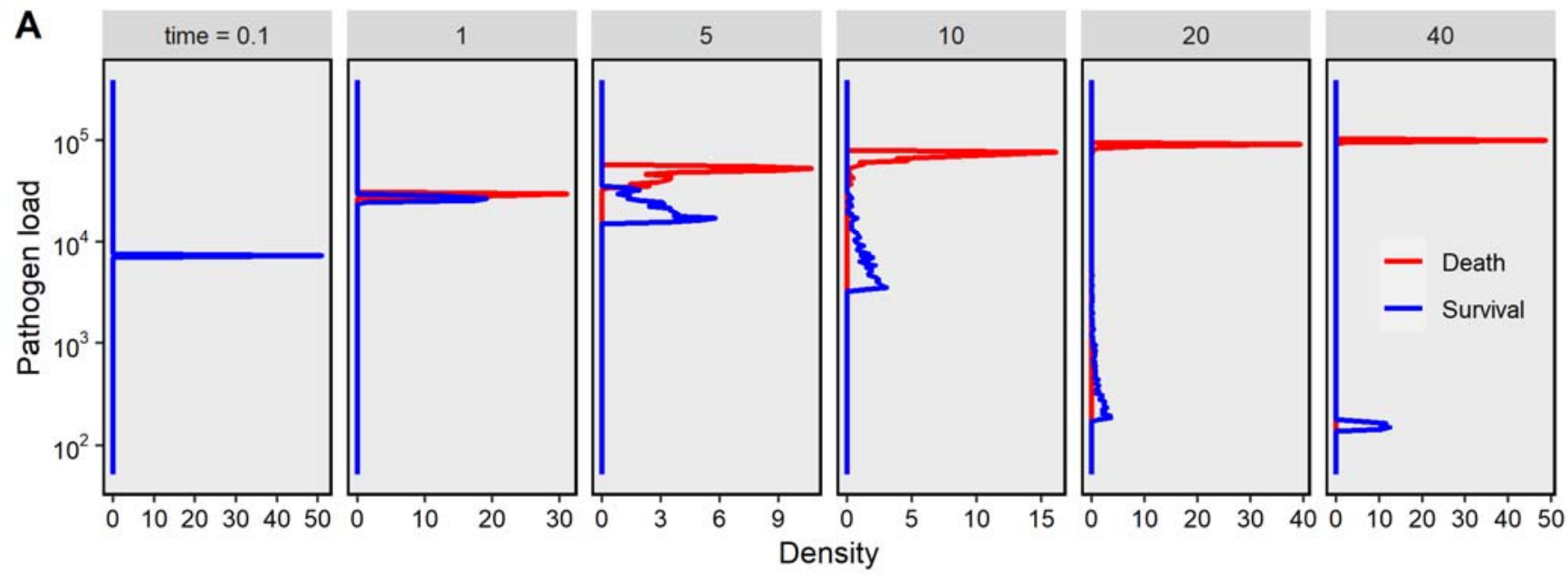

B

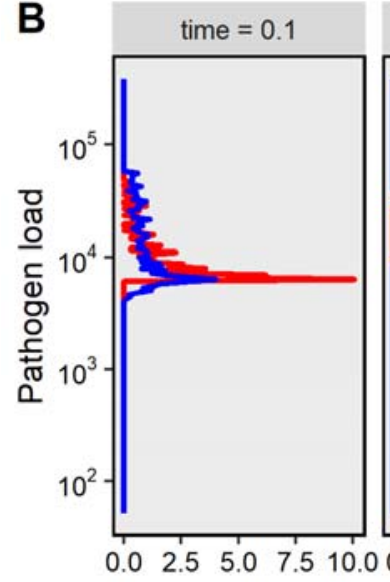

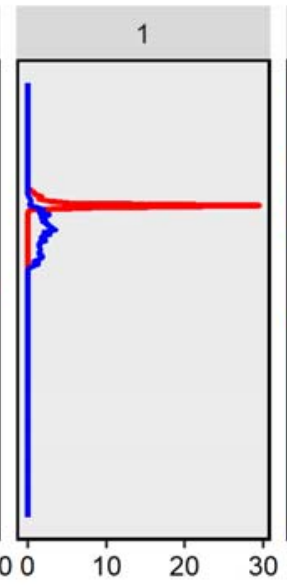
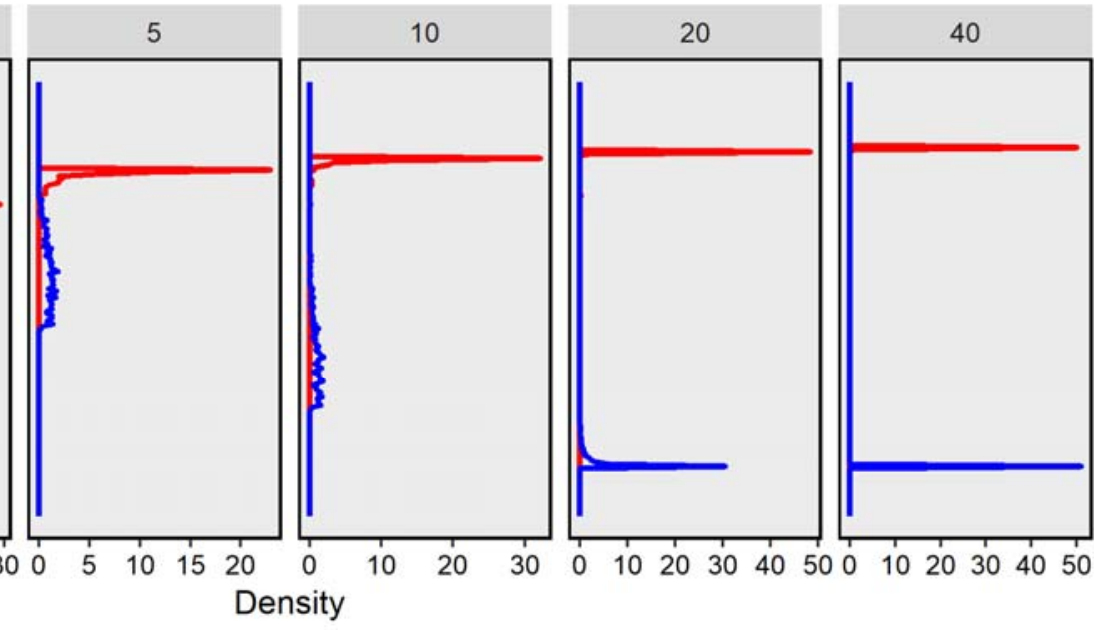

500 Fig. 4 Bistability leads to variations in pooled time-series data. We numerically solve the model with 501 varied immune response rates (A) and initial quantity of pathogens (B), in which the distributions of both parameters are following the uniform distribution $\alpha \sim \mathrm{U}[1500,1700]$ and logarithmic uniform distribution $\beta \sim 10^{\wedge} U[2,5]$, respectively. Data sampled from different time points shows large variations with several orders of magnitude. 
bioRxiv preprint doi: https://doi.org/10.1101/2021.04.13.439629; this version posted April 14, 2021. The copyright holder for this preprint (which was not certified by peer review) is the author/funder, who has granted bioRxiv a license to display the preprint in perpetuity. It is made available under aCC-BY-NC-ND 4.0 International license.

505
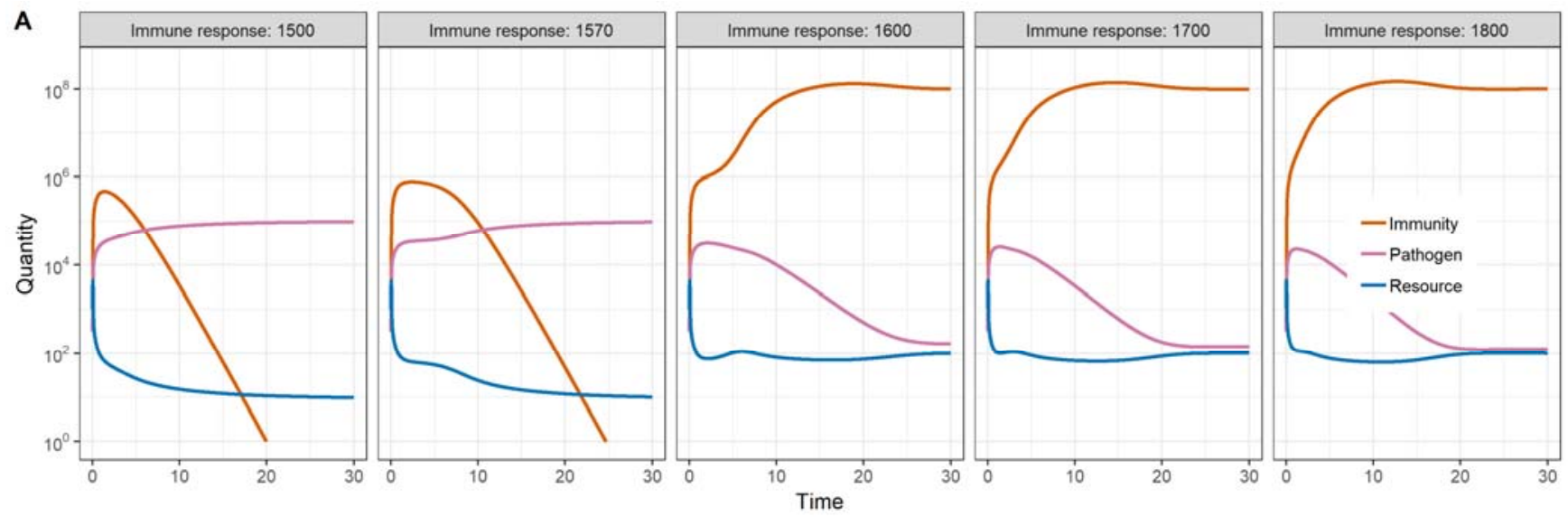

B
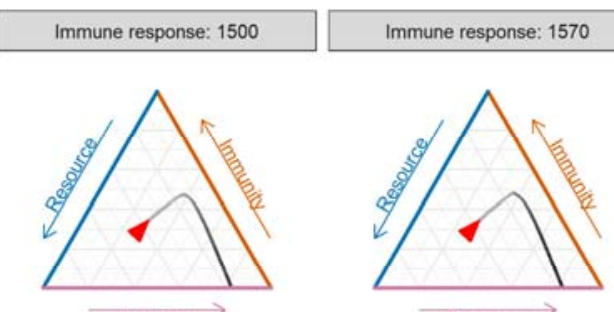

Immune response: 1600

Immune response: 1700

Immune response: 1800

$\stackrel{\text { Pathogen }}{\longrightarrow}$

$\stackrel{\text { Pathoden }}{\longrightarrow}$

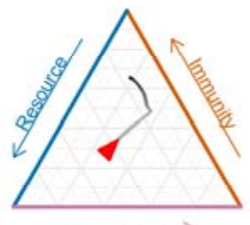

$\stackrel{\text { Pathogen }}{\longrightarrow}$

time $\begin{array}{llll}0 & 10 & 20 & 30\end{array}$

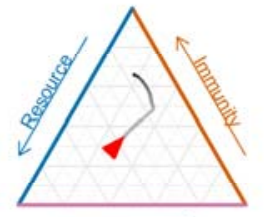

Pathocen

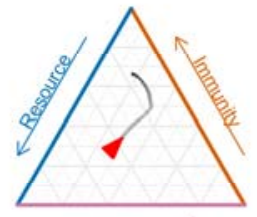

$\underset{\text { Pathogen }}{\longrightarrow}$

506 Fig. S1 The dynamics of immunity, pathogen load, and resource levels for different levels of immune response (A). These patterns fall into two different trajectories (B). 
bioRxiv preprint doi: https://doi.org/10.1101/2021.04.13.439629; this version posted April 14, 2021. The copyright holder for this preprint (which was not certified by peer review) is the author/funder, who has granted bioRxiv a license to display the preprint in perpetuity. It is made available under aCC-BY-NC-ND 4.0 International license.
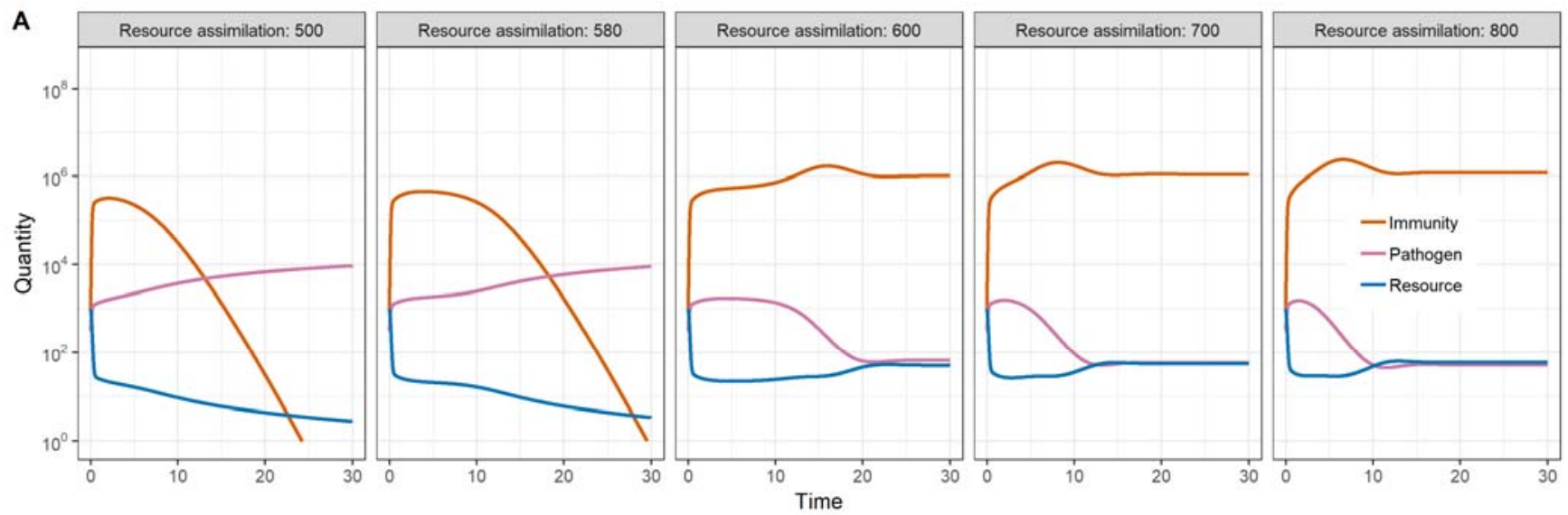

B

Resource assimilation: 500

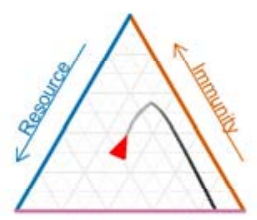

$\underset{\text { Pathogen }}{\longrightarrow}$
Resource assimilation: 580

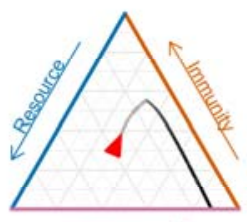

$\stackrel{\text { Pathoden }}{\longrightarrow}$
Resource assimilation: 600

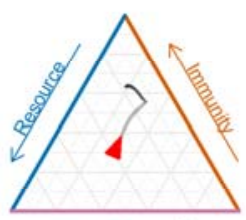

$\underset{\text { Pathogen }}{\longrightarrow}$

time $\begin{array}{llll}0 & 10 \quad 20 & 30\end{array}$
Resource assimilation: 700

Resource assimilation: 800

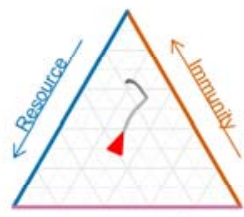

$\underset{\text { Pathocen }}{\longrightarrow}$

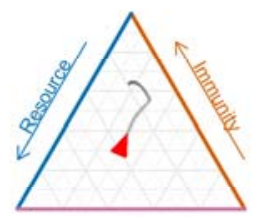

$\stackrel{\text { Pathogen }}{\longrightarrow}$

509 Fig. S2 The dynamics of immunity, pathogen load and resources levels showed different patterns under 510 different levels of resource assimilation (A). These patterns fall into two different trajectories (B). 
bioRxiv preprint doi: https://doi.org/10.1101/2021.04.13.439629; this version posted April 14, 2021. The copyright holder for this preprint (which was not certified by peer review) is the author/funder, who has granted bioRxiv a license to display the preprint in perpetuity. It is made available under aCC-BY-NC-ND 4.0 International license.

A

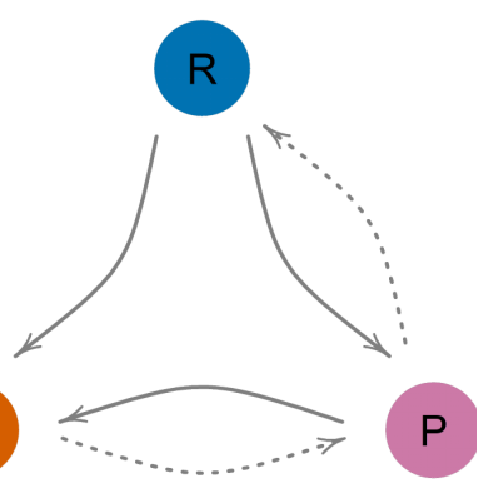

B
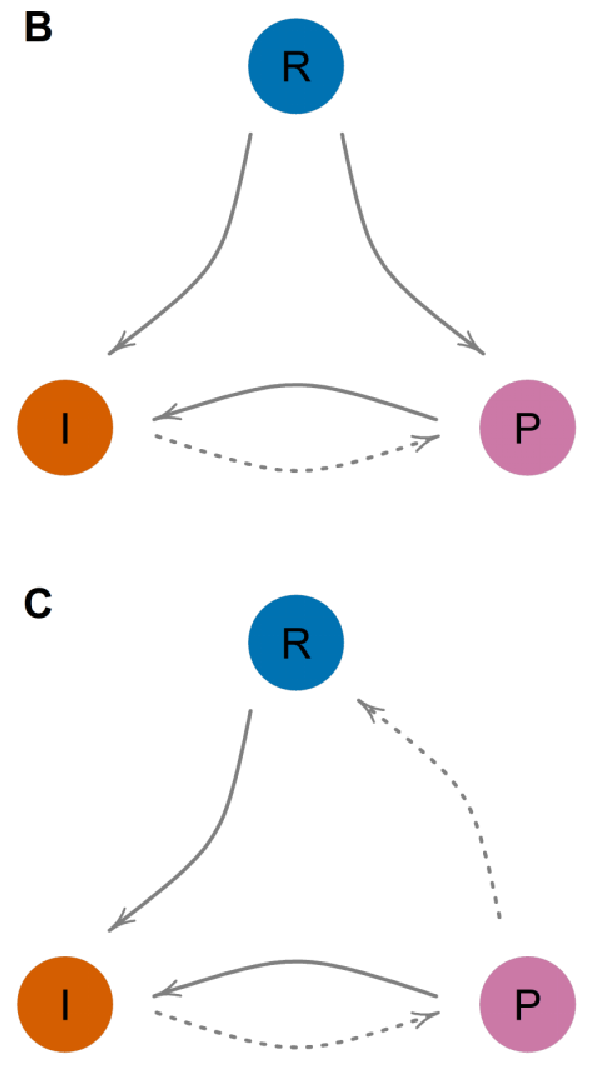

511 resource assimilation and immune response.
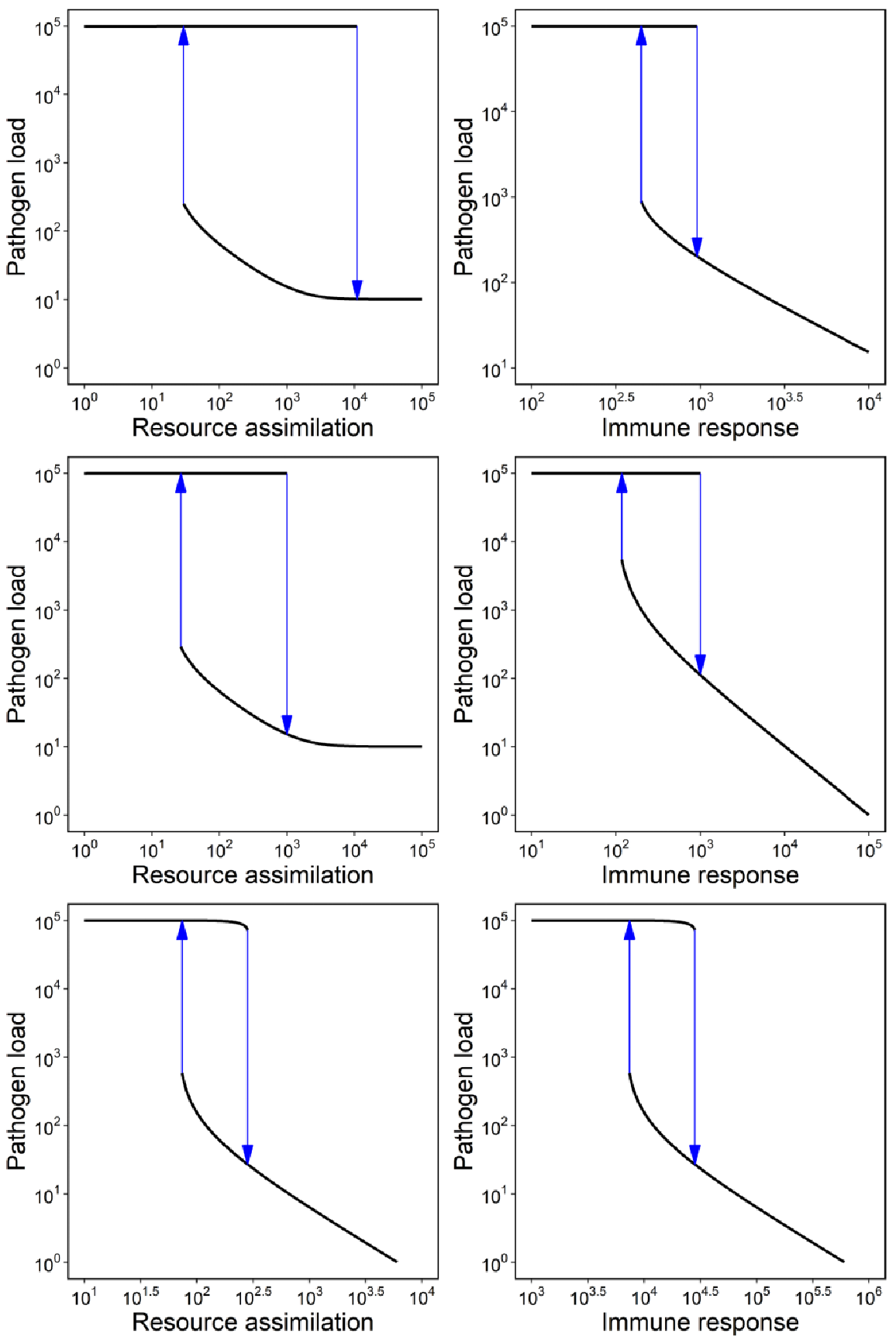

Fig. S3 Infections with different patterns of in-host interaction share the bistability with respect to 

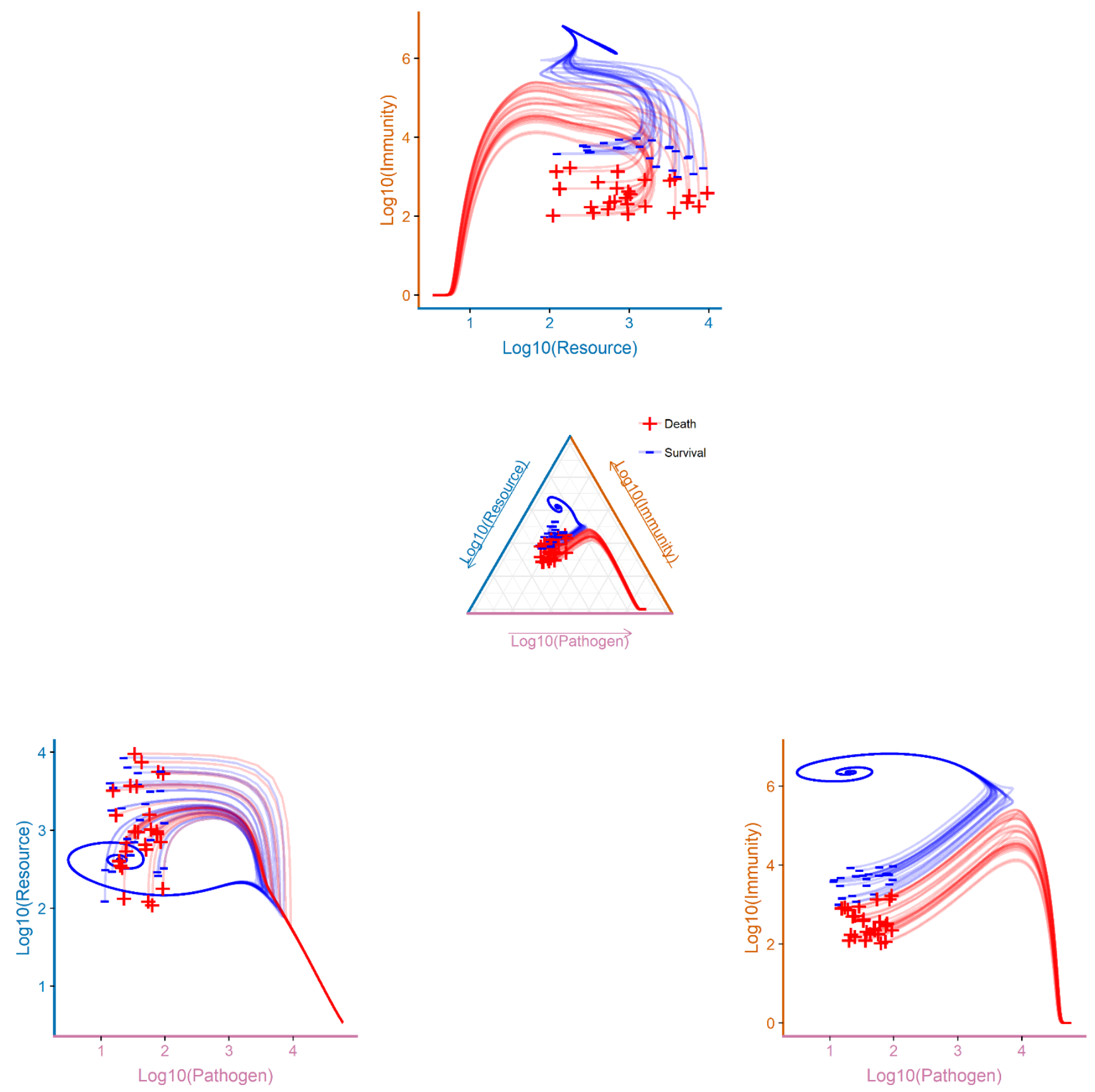

514

515 Fig. S4 The infection trajectories are resembled by two-by-two correlation of resource level, immunity 516 and pathogen load, in which there are always two trajectories representing the consequences of the 517 infection. Red means host killed by pathogens; blue means host overcoming pathogens either killing 518 them all or survive with persistence of low pathogen load. 
519 Table S1.

520 Variables and parameters used in the model. All the default values, if not specified elsewhere, are listed 521 below.

\begin{tabular}{|c|c|c|}
\hline Variables/Parameters & Default values & Description \\
\hline$R$ & $10^{\wedge} 3$ & $\begin{array}{l}\text { Total directly usable resource in host, such as carbohydrates } \\
\text { and amino acids. }\end{array}$ \\
\hline$P$ & $10^{\wedge} 2.5$ & Pathogen load. \\
\hline$I$ & $10^{\wedge} 3$ & $\begin{array}{l}\text { Overall immunity level, which includes blood cells related to } \\
\text { immune function, immune peptides phenoloxidases and other } \\
\text { related antipathogen enzymes. }\end{array}$ \\
\hline$\Omega$ & $10^{\wedge} 5$ & $\begin{array}{l}\text { Physiological and physical carrying capacity of pathogens in } \\
\text { host. }\end{array}$ \\
\hline$\Theta_{P \rightarrow R}$ & $10^{\wedge} 4$ & $\begin{array}{l}\text { Threshold values of pathogens for affecting resource } \\
\text { assimilation. }\end{array}$ \\
\hline$\Theta_{P \rightarrow I}$ & $10^{\wedge} 2$ & $\begin{array}{l}\text { Threshold values of pathogens for initiating immune } \\
\text { response. }\end{array}$ \\
\hline$\Theta_{I}$ & $10^{\wedge} 6$ & Threshold values of immunity for killing pathogens. \\
\hline$C$ & 1 & Total in-take food. \\
\hline$\alpha$ & $10^{\wedge} 4$ & Rate of resource assimilation. \\
\hline$\beta$ & 3000 & $\begin{array}{l}\text { Rate of immune response, for example, the rate of generating } \\
\text { immune substance. }\end{array}$ \\
\hline$\gamma$ & 1 & Growth rate of pathogen. \\
\hline$\delta_{R}$ & 1 & Rate of resources consumption by host. \\
\hline$\delta_{I}$ & 1 & Clearing rate of immune substance. \\
\hline$\delta_{P}$ & 1 & Clearing rate of pathogen. \\
\hline$\varepsilon$ & $10^{\wedge}-2$ & Rate of resource consumption of pathogen. \\
\hline$\lambda$ & $10^{\wedge}-5$ & Rate of resource consumption of immunity. \\
\hline$\kappa$ & 1 & Hill coefficient for pathogens. \\
\hline$\eta$ & 2 & Hill coefficient for immunity. \\
\hline
\end{tabular}

